\title{
Three-Dimensional Evaluation of the Effects of Kinesio Taping on Postoperative Swelling and Pain after Surgically Assisted Rapid Palatal Expansion
}

\author{
Murat Ulu ${ }^{1}$, Özgür Gözlüklü², Çiğdem Kaya ${ }^{1}$, Nuri Ünal ${ }^{1}$, Hüseyin Akçay ${ }^{1}$ \\ ${ }^{1}$ Department of Oral and Maxillofacial Surgery, Faculty of Dentistry, İzmir Katip Çelebi University, İzmir, Turkey. \\ ${ }^{2}$ Oral and maxillofacial surgeon, private practice, İzmir, Turkey.
}

\author{
Corresponding Author: \\ Murat Ulu \\ Aydınlıkevler mh., Cemil Meriç blv., Çiğli/İzmir \\ Turkey \\ Phone: +905426738078 \\ Fax: +90(232) 3860888 \\ E-mail: muratulu81@,hotmail.com, murat.ulu@ikc.edu.tr
}

\begin{abstract}
Objectives: The purpose of the present study was to evaluate the effects of kinesio taping on pain and swelling after surgically assisted rapid palatal expansion.

Material and Methods: A total of 21 (12 male and 9 female) patients with transverse maxillary deficiency were enrolled in the study. Kinesio taping (KT) was applied unilaterally in each patient, whereby sides of the face with KT application were included into the (a) KT group and the other sides were included into the (b) non-KT group. Changes in facial volume were evaluated on digital images using the 3dMD Face System. Pain scores were assessed at postoperative days 1, 2, 3, 4, 5, 6, and 7 using the visual analog scale (VAS). Two-way repeated measures analysis of variance and Mann Whitney U test were used for statistical analyses.

Results: Swelling was significantly lower in the KT group compared to the non-KT group from T0 to T1 (36.42 [SD 19.71] $\mathrm{mm}^{3}$ vs. 183.84 [SD 49.33] $\mathrm{mm}^{3}$ ) and was significantly greater in the non-KT group compared to the KT group from T0 to T2 $\left(70.88\right.$ [SD 15.73] $\mathrm{mm}^{3}$ vs. 21.46 [SD 13.39] $\left.\mathrm{mm}^{3}\right)(\mathrm{P}<0.001$ for both). The VAS scores were significantly lower in the KT group compared to the non-KT group at all time points $(\mathrm{P}<0.05)$.

Conclusions: The application of kinesio taping after maxillofacial surgery reduced the pain and swelling in the postoperative period. Kinesio taping can be used as an alternative to other methods that are used for the reduction of postoperative complaints.
\end{abstract}

Keywords: edema; kinesio tape; maxillary expansion; pain; three-dimensional image.

\section{Accepted for publication: 14 December 2018}

To cite this article:

Ulu M, Gözlüklü Ö, Kaya Ç, Ünal N, Akçay H.

Three-Dimensional Evaluation of the Effects of Kinesio Taping on Postoperative Swelling and Pain after Surgically Assisted Rapid Palatal Expansion

J Oral Maxillofac Res 2018;9(4):e3

URL: http://www.ejomr.org/JOMR/archives/2018/4/e3/v9n4e3.pdf

doi: $10.5037 /$ jomr.2018.9403 


\section{INTRODUCTION}

Transverse maxillary deficiency (TMD) is among the most important dentofacial dysplasias encountered in clinical practice. This skeletal dysplasia was first treated by Angell in 1860 by expanding the maxillary transverse width through midpalatal suture opening by using orthodontic appliances $[1, \underline{2}]$. However, the treatment of TMD with orthodontic appliances alone is not always possible as it depends on the severity of malocclusion, patient age, and the characteristics of midpalatal suture. For such cases, a novel technique known as surgically assisted rapid palatal expansion (SARPE) has been recommended, particularly for patients with maxillary collapse and retrusion $[\underline{2}, \underline{3}]$. Proven as a successful technique, SARPE is frequently used in clinical practice and provides surgical relief in the regions resistant to expansion including midpalatal suture, nasomaxillary suture, nasomaxillary buttress, zygomaticomaxillary buttress, and pterygomaxillary buttress. After the administration of SARPE, the maxilla can be expanded in the transverse direction by using orthodontic appliances $[4,5]$.

SARPE is a distraction osteogenesis of the deficient maxillae in the transverse direction. The osteotomy technique of SARPE is similar to that of Le Fort I osteotomy except for minor differences. In SARPE, unlike in Le Fort I osteotomy, a midline osteotomy is performed to surgically separate the palatal sutures, and a tooth-borne or bone-borne palatal distraction appliance is placed and activated to gradually expand the palate after surgery until the desired position is achieved [,,$\underline{7}]$. Periodontal bone loss, tooth devitalization, and asymmetric expansion are most commonly reported complications after SARPE [7]. Moreover, as can be seen after any oral and maxillofacial surgery procedure, haemorrhage, oedema and, pain may also occur after SARPE. Several approaches have been reported in the literature for the reduction of postoperative oedema and pain, including anti-inflammatory and analgesic drugs, corticosteroid injection, manual lymphatic drainage, cold compression, and low-level laser therapy (LLLT) [ㅇ-12].

Kinesio taping (KT), a technique of applying elastic bandages and tapes, was first used by Dr. Kenzo Kase in the 1970s [13]. KT was developed for sports injuries and is believed to support damaged tissues (i.e. muscles and joints), thereby leading to pain relief. KT has also been shown to be an effective method in the management of lymphedema [14-16]. The general idea in KT is that the tapes used in KT lift the skin and thereby improve blood and lymph flow by reducing haemorrhage and congestion of lymphatic fluid. Additionally, after applying KT, the fluids in spaces are encouraged to move from the areas of higher pressure toward the areas of lower pressure in the desired direction of drainage under the guidance of the tape $[16,17]$. However, although there is a significant accumulation of clinical and practical experience in this approach, there is a limited number of published controlled studies related to KT.

The aim of this clinical study was to evaluate the effects of kinesio taping on postoperative pain and swelling after surgically assisted rapid palatal expansion. We hypothesized that the use of kinesio taping after surgically assisted rapid palatal expansion would reduce postoperative pain and swelling.

\section{MATERIAL AND METHODS Patients}

The randomized double-blind study included 21 (12 male and 9 female) patients who underwent SARPE due to TMD at Department of Oral and Maxillofacial Surgery, Faculty of Dentistry, İzmir Katip Çelebi University, from January 10, 2018 to September 3, 2018. Patients with TMD that cannot be treated only with orthodontic appliances were included in this study. Exclusion criteria were syndromes like craniofacial deformities, patients with systemic disorders, tobacco use and pregnancy. All the patients were treated with tooth-borne expansion devices. After the SARPE procedure, KT was applied unilaterally in each patient, whereby the sides of the face with KT application were included into the (a) $\mathrm{KT}$ group and the other sides were included into the (b) non-KT group. Figure 1 presents the flowchart of the research design employed in the study.

The study was approved by both the Local Ethics Committee (Clinical Research Ethics Committee of İzmir Katip Çelebi University, Faculty of Medicine) and the Ministry of Health Ethics Committee of Republic of Turkey (E.113101). An informed consent was obtained from each patient prior to the study.

\section{Surgical technique}

All the surgeries were performed under general anaesthesia with nasal intubation by the same oral and maxillofacial surgeon (MU). The operations were performed by administering a standardized protocol and the standardized intraoral approaches. A mucoperiosteal incision was made $5 \mathrm{~mm}$ over the mucogingival junction, from the maxillary canine 




Figure 1. Flowchart of the study.

to the first molar bilaterally, by using monopolar cautery with a Colorado microdissection needle (Üzümcü, Ankara, Turkey). Maxillary bone cutting was performed $5-7 \mathrm{~mm}$ over the tooth apex from the lateral nasal wall to the pterygoid plates using a microsaw (NSK, Tochigi, Japan) and osteotomes (KLS Martin, Tuttlingen, Germany) bilaterally. An additional $2 \mathrm{~cm}$ long incision was made between the central maxillary incisors from the mucogingival junction to the labial mucosa along the labial frenulum by using a scalpel. Midline bone cutting was performed with piezosurgery (NSK, Tochigi, Japan) and osteotomy was deepened interdentally between the maxillary incisors (Figure 2). After all osteotomies were completed, the hyrax screw was activated with a one- quarter turn for 10 times to check the mobilization of the segments. After ensuring that there was no problem, the transpalatal distractor was turned back and the mucoperiosteal flaps were closed with 4-0 vicryl suture (Dogsan, Trabzon, Turkey). The patients were discharged on the same day and all the patients received the same postoperative medication, including paracetamol $500 \mathrm{mg}$ (Parol; Atabay Pharmaceutical Ltd, Istanbul, Turkey) $2 \times 1$ for 3 days and $100 \mathrm{mg}$ doxycycline (Monodoks; Deva, Atabay Pharmaceutical Ltd, Istanbul, Turkey) $2 \times 1$ for 5 days orally (Deva; Istanbul, Turkey) 2 x 1 for 5 days orally. No ice pack application was performed and no intraoperative or postoperative corticosteroids were administered. The postoperative period was uneventful in all the patients.



Figure 2. $\mathrm{A}=$ Lateral view of the maxilla after mucoperiosteal flap elevation.

$\mathrm{B}=$ Maxillary bone osteotomy was performed from the lateral nasal wall to the pterygoid plates using a microsaw.

$\mathrm{C}=$ Maxillary lateral wall and midline bone cutting were performed bilaterally. 


\section{Taping}

KT was applied in all the patients by the same surgeon as described in the literature. The skin was cleaned with alcohol and in the male patients, the application area was shaved before the taping procedure. Blackcolour Kinesio-Tex Gold ${ }^{\circledR}$ tapes $(50 \mathrm{~mm}$ x $5 \mathrm{~m})$ (Kinesio Holding Corporation, USA) were used in all the patients. The tapes were divided into 3 equal parts until the base. The undivided end of the tapes was positioned just above the supraclavicular nodes and 3 equal strips were placed on the skin slightly below the level of the zygomatic arch with $20 \%$ tension. Lymphatic tapes were directed at the appropriate lymphatic duct crossing the cervical, submental, mandibular, submandibular, preauricular and parotid nodes reaching the zygomatic buttress and the zygomatic arch. After application, the tapes were gently massaged to facilitate activation. The tapes were changed at postoperative day 2 in order to perform a face scan with $3 \mathrm{dMD}$ Face System (3dMD, Atlanta, USA) for the assessment of swelling. The tapes were maintained on the face of each patient for a total period of 7 days (Figure 3 ).

\section{Assessment of swelling}

Swelling was assessed at three time points: preoperatively (baseline) (T0), at postoperative day 2 (T1) and at postoperative day 7 (T2). The changes in facial volume were evaluated on digital images using the $3 \mathrm{dMD}$ Face System and the images were analysed using the $3 \mathrm{dMD}$ Vultus software (3dMD, Atlanta, USA) (Figure 4).

\section{Assessment of pain}

Pain assessment was performed using the visual analog scale (VAS). VAS is tool used for pain assessment involving a $100 \mathrm{~mm}$ long horizontal line with verbal descriptors at each end to express the extremes of the feeling and represents all pain sensations from none to maximum, where 0 indicates no pain, 50 moderate pain, and 100 indicates the worst pain possible. Patients were asked to place a mark along the line that corresponded to the severity of the pain they were experiencing. Pain scores were recorded at postoperative days $1,2,3,4,5,6$ and 7.

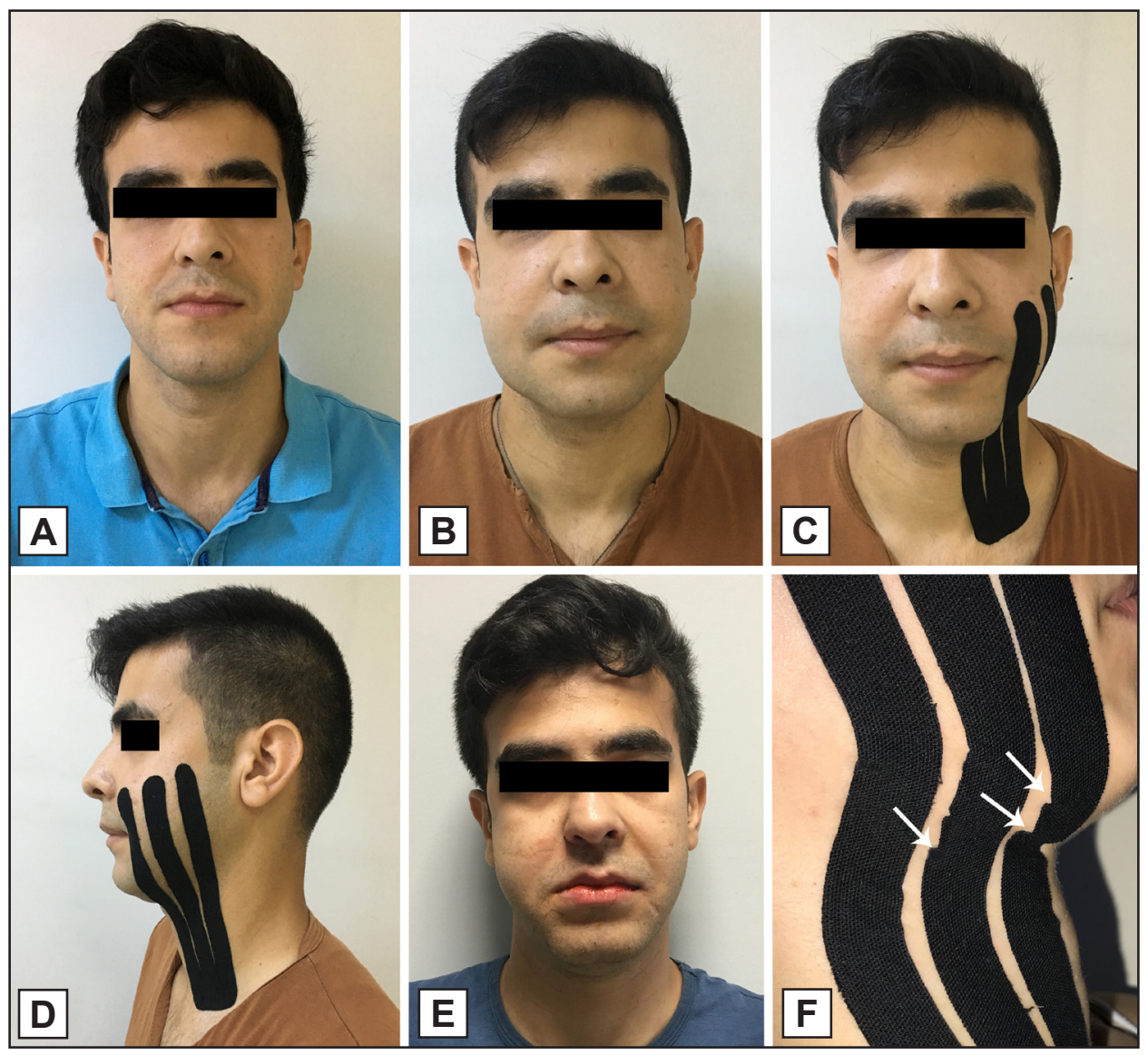

Figure 3. Preoperative view of the patient (A). The tapes were changed at postoperative day 2 to perform a face scan with $3 \mathrm{dMD}$ Face System for the assessment of swelling. Swelling was greater on the right side (non-KT group) compared to the left side (KT-group) (B). Application of the kinesio taping (KT) from the supraclavicular nodes to below the level of the zygomatic arch (C,D). Frontal view of patient on day 7 after surgery $(\mathrm{E})$. White arrows indicate the skin folds $(\mathrm{F})$ 


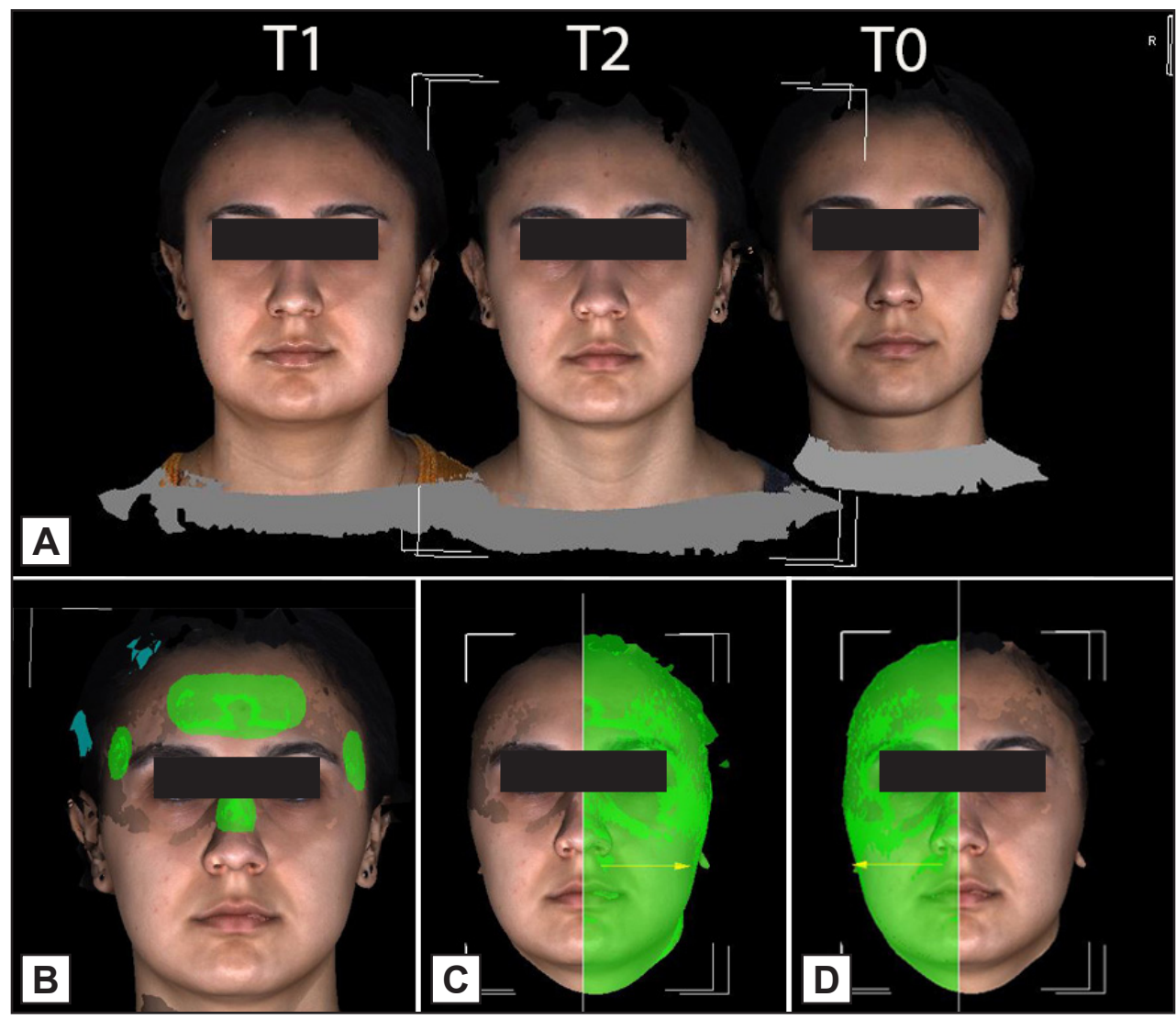

Figure 4. $\mathrm{A}=$ Preoperative (T0), postoperative day 2 (T1) and postoperative day 7 (T2) views of the patient. $\mathrm{B}=$ Superposition of the reference fields. $\mathrm{C}$ and $\mathrm{D}=$ Calculation of the volumetric changes on the overlapped images.

\section{Statistical analysis}

Data were analysed using IBM SPSS Statistics for Windows version 25.0 (Armonk, NY: IBM Corp). Data were expressed as mean, standard deviation (SD), median, first quartile value, and third quartile value $\left[\mathrm{M}\left(\mathrm{Q}_{1}-\mathrm{Q}_{3}\right)\right]$. Two-way repeated measures analysis of variance (ANOVA) was used to compare the changes in the facial volume at three time points (T0, T1, T2). Bonferroni correction was performed to compare the main effects of the procedure. Mann-Whitney $U$ test was used to compare the variables with nonnormal distribution between two groups. $\mathrm{P}$ value of $<0.05$ was considered significant.

\section{RESULTS}

Twenty-one (12 male and 9 female; age range, 17 - 26 years) patients with transverse maxillary deficiency were included in the present study.

\section{Swelling}

Swelling measurements were performed using the $3 \mathrm{dMD}$ Face System and the 3dMD Vultus program. A significant difference was found between the changes in the swelling measurements from $\mathrm{T} 0$ to $\mathrm{T} 1$ and from T0 to T2. Moreover, a significant difference was found between the KT and non-KT groups with regard to these changes ( 0.001 for all) (Table 1, Figure 5). In the KT group, the difference between the facial volume at $\mathrm{T} 1$ and at T0 was $36.42(19.71) \mathrm{mm}^{3}$ and the difference between the facial volume at $\mathrm{T} 2$ and at T0 was $21.46(13.39) \mathrm{mm}^{3}$, both of which were statistically significant $(\mathrm{P}<0.001)$.

In the non-KT group, the difference between the facial volume at $\mathrm{T} 1$ and at $\mathrm{T} 0$ was $183.84(49.33) \mathrm{mm}^{3}$ and the difference between the facial volume at $\mathrm{T} 2$ and at T0 was $70.88(15.73) \mathrm{mm}^{3}$, both of which were statistically significant $(\mathrm{P}<0.001)$.

Table 1. Changes in swelling from $\mathrm{T} 0$ to $\mathrm{T} 1$ from $\mathrm{T} 0$ to $\mathrm{T} 2$

\begin{tabular}{|c|c|c|c|}
\hline \multirow{3}{*}{ Volume } & \multicolumn{2}{|c|}{ Groups } & \multirow{3}{*}{$\mathbf{P}$ (intergroup) } \\
\hline & $\begin{array}{c}\text { KT } \\
(n=21)\end{array}$ & $\begin{array}{l}\text { Non-KT } \\
(\mathrm{n}=\mathbf{2 1})\end{array}$ & \\
\hline & Mean (SD) & Mean (SD) & \\
\hline T0-T1 & $36.42(19.71)$ & $183.84(49.33)$ & $<0.001$ \\
\hline T0-T2 & $21.46(13.39)$ & $70.88(15.73)$ & $<0.001$ \\
\hline $\mathbf{P}\left(\right.$ intragroup) ${ }^{\mathrm{a}}$ & $<0.001$ & $<0.001$ & \\
\hline
\end{tabular}

a Statistically significant at the level $\mathrm{P}<0.05$ (ANOVA test). $\mathrm{KT}=$ kinesio taping; $\mathrm{T} 0=$ before surgery (baseline); $\mathrm{T} 1=$ postoperative day $2 ; \mathrm{T} 2=$ postoperative day $7 ; \mathrm{SD}=$ standard deviation. 




Figure 5. $\mathrm{A}=$ Comparison of the volumetric differences between the $\mathrm{KT}$ and non-KT groups with regard to the time intervals $\mathrm{T} 0-\mathrm{T} 1$ and $\mathrm{T} 0-\mathrm{T} 2 . \mathrm{B}=$ Comparison of the volumetric differences between the time intervals T0-T1 and T0-T2 in both groups.

Swelling was significantly lower in the KT group compared to the non-KT group from T0 to T1 $(36.42$ [19.71] $\mathrm{mm}^{3}$ vs. 183.84 [49.33] $\left.\mathrm{mm}^{3}\right)$ and was significantly greater in the non-KT group compared to the KT group from T0 to T2 $\left(70.88[15.73] \mathrm{mm}^{3} \mathrm{vs}\right.$. $\left.21.46[13.39] \mathrm{mm}^{3}\right)(\mathrm{P}<0.001$ for both $)$.

\section{Pain}

The VAS scores were significantly lower in the KT group compared to the non-KT group at all time points $(\mathrm{P}<0.05)$. Of note, the highest level of significance was revealed for the days $1,2,5$, and 7 $(P=0.001)$ (Table 2, Figure 6).

\section{DISCUSSION}

Postoperative swelling and pain are common complications occurring secondary to oral and maxillofacial surgery, both of which decrease the quality of life of the patients and affect their daily life activities. For this reason, numerous clinical studies have been conducted to reduce postsurgical discomfort [16-18]. The aim of this study was to evaluate the effects of KT application on swelling and pain after SARPE. The authors hypothesized that the use of KT would decrease the severity of swelling and pain in the early postoperative period and the results indicated that the KT application after SARPE significantly reduced the swelling and pain within the first days after surgery.

SARPE is a distraction indicated in patients with maturation of sutures that have transverse maxillary deficiency. SARPE, which was first described by Bell and Epker [19], is considered to be a reliable
Table 2. VAS scores

\begin{tabular}{|c|c|c|c|}
\hline \multirow{3}{*}{ VAS } & \multicolumn{2}{|c|}{ Groups } & \multirow{3}{*}{$\mathbf{P}^{\mathrm{a}}$} \\
\hline & $\begin{array}{c}\text { KT } \\
(n=21)\end{array}$ & $\begin{array}{c}\text { Non-KT } \\
(n=21)\end{array}$ & \\
\hline & $M\left(Q_{1}-Q_{3}\right)$ & $M\left(Q_{1}-Q_{3}\right)$ & \\
\hline Day 1 & $50(40-62.5)$ & $60(47.5-70)$ & 0.001 \\
\hline Day 2 & $40(30-50)$ & $50(40-60)$ & 0.001 \\
\hline Day 3 & $30(20-50)$ & $40(30-50)$ & 0.017 \\
\hline Day 4 & $20(12.5-32.5)$ & $30(20-40)$ & 0.006 \\
\hline Day 5 & $10(5-25)$ & $20(12.5-30)$ & 0.001 \\
\hline Day 6 & $5(0-10)$ & $10(10-20)$ & 0.033 \\
\hline Day 7 & $0(0-10)$ & $10(5-15)$ & 0.001 \\
\hline
\end{tabular}

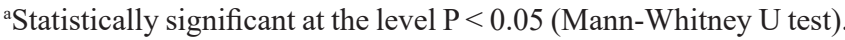
VAS = visual analog scale; $\mathrm{KT}=$ kinesio taping; $\mathrm{M}=$ median; $\mathrm{Q}_{1}=$ first quartile value; $\mathrm{Q}_{3}=$ third quartile value.

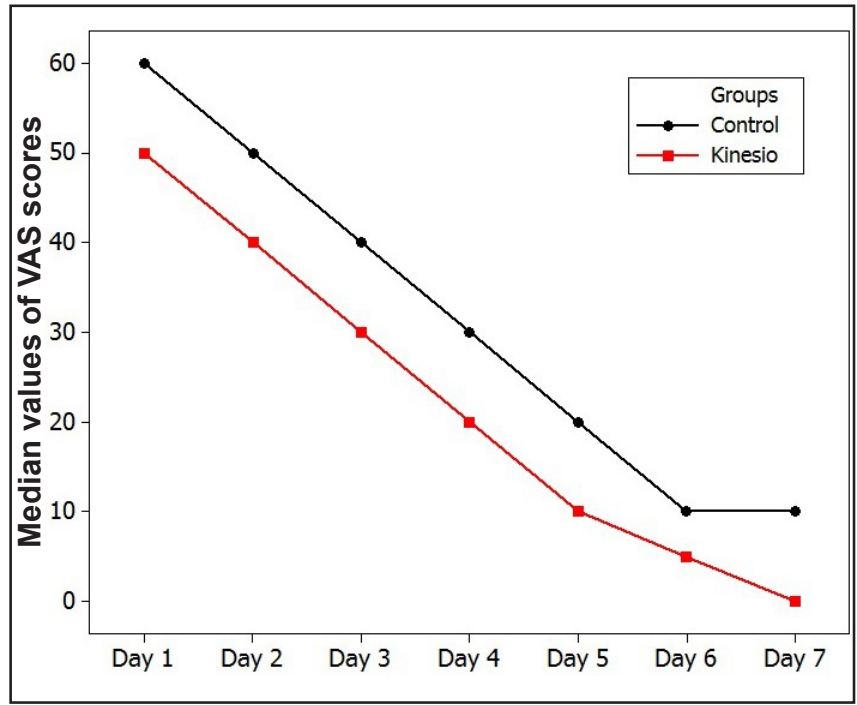

Figure 6. VAS scores were significantly lower in KT group compared to non-KT group at all time points. 
procedure with little risk of life-threatening complications. Through a combination of orthodontic and surgical procedures, SARPE allows maximum expansion of the maxilla. In the present study, SARPE was administered as described by Bell and Epker [19] with little modifications and all the surgeries were completed with no complications. Moreover, the desired maxillary expansion was achieved in all the patients in the postoperative period.

Literature reviews indicate that numerous clinical studies have been conducted to reduce postoperative oedema and pain in the maxillofacial area. SemperHogg, for instance, reported that the preoperative injection of single-dose dexamethasone reduced postoperative oedema after orthognathic surgery [20]. Similarly, another study showed that the preoperative intramuscular injection of single-dose dexamethasone was an effective method for decreasing pain and swelling after third molar surgery [21]. Cooling of the face is a commonly used procedure to increase patient comfort after maxillofacial surgeries. Rana et al. [222] and Karmi et al. [23] indicated that the cooling of the face was effective in reducing postoperative swelling and pain. On the other hand, laser treatment is also frequently used for the reduction of pain and swelling after surgery. Of note, LLLT has been shown to be a beneficial method for increasing patient satisfaction in the postoperative period $[\underline{17}, \underline{18}, \underline{24}, \underline{25}]$.

Oedema is a clinical condition basically defined as the accumulation of excessive plasma proteins in the tissue space which occurs when the lymphatic fluid exceeds the capacity of lymphatic system [26]. Manual lymphatic drainage (MLD), a technique first described by Vodder [27], is primarily used for regulating the equilibrium between the lymphatic fluid load and the drainage capacity of the lymphatic system. MLD is mostly applied in cancer patients undergoing surgery and has been recently used for the reduction of postoperative oedema and pain in the maxillofacial area. Ferreira et al. [28] evaluated the effects of MLD after alveolar bone grafting surgery and reported that MLD significantly reduced the pain and swelling in the early postoperative period. Renato et al. [27] investigated the effects of MLD on postoperative facial swelling and pain in patients undergoing bimaxillary orthognathic surgery and revealed that although MLD was effective in decreasing postoperative facial volume measurements, no difference was found between the groups with regard to the pain and swelling perceptions of the patients.

KT has long been used in the prevention and treatment of musculoskeletal pain and injuries [15]. KT has different clinical application areas and has been shown to provide favourable outcomes in patients with low- back pain [29], in pain relief and the improvement of physical functions in patients with knee osteoarthritis [30], in the treatment of carpal tunnel syndrome [31] and in the treatment of functional disorders of masticatory muscles [32]. Although KT is more frequently used in the treatment of sports injuries (i.e. joint and muscle disorders), the use of KT has recently become an alternative method in the management of lymphoedema. The popular hypothesis about KT posits that KT reduces the pain by elevating the skin and facilitating the lymph flow. In KT, the fluids are guided to move from the higher pressure areas towards the lower pressure areas into the created space and are directed by the tape to the preferred direction of drainage $[\underline{15}, \underline{16}]$. KT has been shown to be an effective method for reducing lymphedema in studies evaluating the effects of KT in the reduction of lymphedema in patients with breast cancer [33], mastectomy [34], and total knee arthroplasty [35]. However, although some other studies suggested that $\mathrm{KT}$ has no effect on postoperative pain reduction [3638], Kase et al. [15] claimed that KT can reduce pain by alleviating pressure on nociceptors. In agreement with Kase et al. [15], the present study indicated that the patients in the KT group experienced significantly less pain compared to the patients in the non-KT group. Moreover, the VAS scores indicated moderate pain in both groups $(50 \leq$ VAS $\leq 60)$ at postoperative day 1 , which gradually decreased over the following days. However, although the KT group had significantly less pain compared to the non-KT group, this finding may be misleading since one side of the same patient's face was in the KT group while the other side was in the non-KT group and thus the patients might have had difficulty in identifying which side had greater pain due to the reflected pain.

There are very few clinical studies reporting on the use of KT in postoperative management of swelling and pain after maxillofacial surgeries. Ristow et al. [39] investigated the efficacy of KT after wisdom teeth extraction and reported that a significant reduction was achieved in all the postoperative parameters including swelling, pain, and trismus. Tozzi et al. [40] and Danuta et al. [41] evaluated the effects of KT on swelling after orthognathic surgery and both studies indicated that $\mathrm{KT}$ is a beneficial method for overcoming postoperative swelling. In two other studies, Ristow et al. [36, $\underline{37]}$ applied KT after surgical treatment of patients with zygomatico-orbital and mandibular fractures and reported that KT led to decreased swelling and increased patient satisfaction in the early postoperative period although it had no significant effect on pain control and trismus.

To the best of our knowledge, this paper is the first to 
investigate the effects of $\mathrm{KT}$ on postoperative swelling and pain after SARPE. The results of the study indicated that the application of KT after SARPE significantly reduced postoperative swelling and pain. Literature indicates that postoperative swelling reaches its maximum level within 2 - 3 days after surgery [37]. Accordingly, in our study, facial volume measurements were performed at postoperative days 0,2 and 7 to evaluate oedema. The measurements showed that the increase in the facial volume at day 2 was 4 times greater in the non-KT group than in the KT group. However, at day 7 (the day of appointment for removing the sutures), swelling was significantly lower in the KT group than in the non-KT group. These findings indicate that the application of KT after maxillary osteotomy led to effective outcomes in the reduction of postoperative swelling, which was consistent with the literature $[\underline{36}, 37,39-41]$.

A number of methods have been suggested for the measurement of postoperative changes in facial volume, including verbal response scale, linear measurements (marking reference landmarks on the face), photographic technique, and magnetic resonance imaging [37,42-44]. Craniofacial anthropometry using the 3dMD Face System is a valid and reliable technique [45]. Additionally, Fredrik et al. [46] suggested that the virtual three-dimensional models derived from the 3dMD Face System provide not only a high level of technical precision, but also high intra- and inter-observer reliability regarding landmark identification. In our study, we also used the 3dMD Face System for the measurement of postoperative changes in facial volume to obtain realistic and reliable results.

\section{CONCLUSIONS}

The application of kinesio taping after maxillofacial surgery provides lower pain and swelling in the postoperative period. Moreover, kinesio taping is a simple and economical method with no side effects. Kinesio taping can be used as an alternative or additional method to other methods that are used to increase patient comfort in the postoperative period. Further studies are needed to compare the effectiveness of kinesio taping in postsurgical recovery in combination with other methods including laser treatment or steroid therapy.

\section{ACKNOWLEDGMENTS AND DISCLOSURE STATEMENTS}

The authors would like to thank Dr. Ferhan Elmal (Department of Biostatistics, Faculty of Medicine, İzmir Katip Çelebi University) for his assistance in statistical analysis. There are no conflicts of interest related to this research. This study was completely financed by the authors.

\section{REFERENCES}

1. Angell EH. Treatment of irregularity of the permanent or adult teeth. Dent Cosmos. 1860 Jul;1:540-44.

2. Perciaccante VJ, Bays RA. Maxillary orthognatic surgery. In: Miloro M, Ghali GE, Larsen PE, Waite PD, editors. Peterson's principle of oral and maxillofacial surgery second edition. London: BC Decker Inc; 2004. p. 1197-8.

3. Lines PA. Adult rapid maxillary expansion with corticotomy. Am J Orthod. 1975 Jan;67(1):44-56. [Medline: 803165] [doi: 10.1016/0002-9416(75)90128-1]

4. Robiony M, Costa F, Politi M. Ultrasound endoscopic bone cutting for rapid maxillary expansion. J Oral Maxillofac Surg. 2014 May;72(5):980-90. [Medline: 24326019] [doi: 10.1016/j.joms.2013.10.004]

5. Shetty V, Caridad JM, Caputo AA, Chaconas SJ. Biomechanical rationale for surgical-orthodontic expansion of the adult maxilla. J Oral Maxillofac Surg. 1994 Jul;52(7):742-9; discussion 750-1. [Medline: 8006740] [doi: 10.1016/0278-2391(94)90492-8]

6. Moura LB, Spin-Neto R, Sverzut CE, Monnazzi Mda S, Trivellato AE, Gabrielli MA, Pereira-Filho VA. Evaluation of the palatal split pattern in surgically rapid maxillary expansion-comparison of two techniques. Oral Maxillofac Surg. 2016 Sep;20(3):255-8. [Medline: 27154514] [doi: 10.1007/s10006-016-0562-5]

7. Kufta K, Melean LP, Grady MS, Panchal N. Massive Middle Cerebral Artery Infarction After Surgically Assisted Rapid Palatal Expansion: A Case Report. J Oral Maxillofac Surg. 2017 Jul;75(7):1529.e1-1529.e8. [Medline: 28438597] [doi: 10.1016/j.joms.2017.03.036]

8. Dan AE, Thygesen TH, Pinholt EM. Corticosteroid administration in oral and orthognathic surgery: a systematic review of the literature and meta-analysis. J Oral Maxillofac Surg. 2010 Sep;68(9):2207-20. [Medline: 20591548] [doi: 10.1016/j. joms.2010.04.019]

9. Withey S, Pracy P, Wood S, Rhys-Evans P. The use of a lymphatic bridge in the management of head and neck lymphoedema. Br J Plast Surg. 2001 Dec;54(8):716-9. [Medline: 11728118] [doi: 10.1054/bjps.2001.3693] 
10. Glass GE, Waterhouse N, Shakib K. Hilotherapy for the management of perioperative pain and swelling in facial surgery: a systematic review and meta-analysis. Br J Oral Maxillofac Surg. 2016 Oct;54(8):851-856. [Medline: 27516162] [doi: 10.1016/j.bjoms.2016.07.003]

11. Raiesian S, Khani M, Khiabani K, Hemmati E, Pouretezad M. Assessment of Low-Level Laser Therapy Effects After Extraction of Impacted Lower Third Molar Surgery. J Lasers Med Sci. 2017 Winter;8(1):42-45. [Medline: 28912943] [PMC free article: 5420364] [doi: 10.15171/jlms.2017.08]

12. Silva de Oliveira JC, Grossi de Oliveira GA, Bassi AP. Comparative Assessment of the Effect of Ibuprofen and Etodolac on Edema, Trismus, and Pain in Lower Third Molar Surgery: A Randomized Clinical Trial. J Oral Maxillofac Surg. 2016 Aug;74(8):1524-30. [Medline: 27160363] [doi: 10.1016/j.joms.2016.04.003]

13. Coskun Benlidayi I, Salimov F, Kurkcu M, Guzel R. Kinesio Taping for temporomandibular disorders: Singleblind, randomized, controlled trial of effectiveness. J Back Musculoskelet Rehabil. 2016 Apr 27;29(2):373-380. [Medline: 26966829] [doi: 10.3233/BMR-160683]

14. Ristow O, Hohlweg-Majert B, Kehl V, Koerdt S, Hahnefeld L, Pautke C. Does elastic therapeutic tape reduce postoperative swelling, pain, and trismus after open reduction and internal fixation of mandibular fractures? J Oral Maxillofac Surg. 2013 Aug;71(8):1387-96. [Medline: 23676774] [doi: 10.1016/i.joms.2013.03.020]

15. Kase K, Wallis J, Kase T. Clinical therapeutic applications of the Kinesio Taping Method. 2 ed. Tokyo: Ken Ikai; 2003. p. 20.

16. Ristow O, Pautke C, Kehl V, Koerdt S, Hahnefeld L, Hohlweg-Majert B. Kinesiologic taping reduces morbidity after oral and maxillofacial surgery: a pooled analysis. Physiother Theory Pract. 2014 Aug;30(6):390-8. [Medline: 24575949] [doi: 10.3109/09593985.2014.891068]

17. Alan H, Yolcu Ü, Koparal M, Özgür C, Öztürk SA, Malkoç S. Evaluation of the effects of the low-level laser therapy on swelling, pain, and trismus after removal of impacted lower third molar. Head Face Med. 2016 Jul 26;12(1):25. [Medline: 27457369] [doi: 10.1186/s13005-016-0121-1]

18. Pol R, Ruggiero T, Gallesio G, Riso M, Bergamasco L, Mortellaro C, Mozzati M. Efficacy of Anti-Inflammatory and Analgesic of Superpulsed Low Level Laser Therapy After Impacted Mandibular Third Molars Extractions. J Craniofac Surg. 2016 May;27(3):685-90. [Medline: 27159857] [doi: 10.1097/SCS.0000000000002523]

19. Bell WH, Epker BN. Surgical-orthodontic expansion of the maxilla. Am J Orthod. 1976 Nov;70(5):517-28. [Medline: 790971] [doi: 10.1016/0002-9416(76)90276-1]

20. Semper-Hogg W, Fuessinger MA, Dirlewanger TW, Cornelius CP, Metzger MC. The influence of dexamethasone on postoperative swelling and neurosensory disturbances after orthognathic surgery: a randomized controlled clinical trial. Head Face Med. 2017 Nov 7;13(1):19. [Medline: 29116013] [PMC free article: 5678574] [doi: 10.1186/s13005-017-0153-1]

21. Al-Dajani M. Can Preoperative Intramuscular Single-Dose Dexamethasone Improve Patient-Centered Outcomes Following Third Molar Surgery? J Oral Maxillofac Surg. 2017 Aug;75(8):1616-1626. [Medline: 28438596] [doi: 10.1016/i.joms.2017.03.037]

22. Rana M, Gellrich NC, von See C, Weiskopf C, Gerressen M, Ghassemi A, Modabber A. 3D evaluation of postoperative swelling in treatment of bilateral mandibular fractures using 2 different cooling therapy methods: a randomized observer blind prospective study. J Craniomaxillofac Surg. 2013 Jan;41(1):e17-23. [Medline: 22626630] [doi: 10.1016/j.jems.2012.04.002]

23. El-Karmi A, Hassfeld S, Bonitz L. Development of swelling following orthognathic surgery at various cooling temperatures by means of hilotherapy-a clinical, prospective, monocentric, single-blinded, randomised study. J Craniomaxillofac Surg. 2018 Sep;46(9):1401-1407. [Medline: 30031593] [doi: 10.1016/i.jcms.2018.01.012]

24. Baek WY, Byun IH, Yun IS, Kim JY, Roh TS, Lew DH, Kim YS. The effect of light-emitting diode (590/830 nm)based low-level laser therapy on posttraumatic edema of facial bone fracture patients. J Craniomaxillofac Surg. 2017 Nov;45(11):1875-1877.. [Medline: 28986000] [doi: 10.1016/j.jcms.2017.08.027]

25. Petrini M, Ferrante M, Trentini P, Perfetti G, Spoto G. Effect of pre-operatory low-level laser therapy on pain, swelling, and trismus associated with third-molar surgery. Med Oral Patol Oral Cir Bucal. 2017 Jul 1;22(4):e467-e472. [Medline: 28578368] [PMC free article: 5549519] [doi: 10.4317/medoral.21398]

26. Ebert JR, Joss B, Jardine B, Wood DJ. Randomized trial investigating the efficacy of manual lymphatic drainage to improve early outcome after total knee arthroplasty. Arch Phys Med Rehabil. 2013 Nov;94(11):2103-11. [Medline: 23810354] [doi: 10.1016/j.apmr.2013.06.009]

27. Yaedú RYF, Mello MAB, Tucunduva RA, da Silveira JSZ, Takahashi MPMS, Valente ACB. Postoperative Orthognathic Surgery Edema Assessment With and Without Manual Lymphatic Drainage. J Craniofac Surg. 2017 Oct;28(7): 1816-1820. [Medline: 28872503] [doi: 10.1097/SCS.0000000000003850]

28. Ferreira TRR, Sabatella MZ, Silva TMS, Trindade-Suedam IK, Lauris JRP, Trindade Junior AS. Facial edema reduction after alveolar bone grafting surgery in cleft lip and palate patients: a new lymphatic drainage protocol. Rev Gaúcha de Odontol. $2013 \mathrm{Jul}$; 61(3): 341-8. [URL: http://www.revistargo.com.br/viewarticle.php?id=2893]

29. Macedo LB, Richards J, Borges DT, Melo SA, Brasileiro JS. Kinesio Taping reduces pain and improves disability in low back pain patients: a randomized controlled trial. Physiotherapy. 2018 Jul 26. pii: S0031-9406(18)30154-8. [Medline: 30348455] [doi: 10.1016/j.physio.2018.07.005] 
30. Lu Z, Li X, Chen R, Guo C. Kinesio taping improves pain and function in patients with knee osteoarthritis: A meta-analysis of randomized controlled trials. Int J Surg. 2018 Nov;59:27-35. [Medline: 30273684] [doi: 10.1016/j.ijsu.2018.09.015]

31. Aktürk S, Büyükavcı R, Aslan Ö, Ersoy Y. Comparison of splinting and Kinesio taping in the treatment of carpal tunnel syndrome: a prospective randomized study. Clin Rheumatol. 2018 Sep;37(9):2465-2469. [Medline: 29948355] [doi: 10.1007/s10067-018-4176-1]

32. Lietz-Kijak D, Kopacz Ł, Ardan R, Grzegocka M, Kijak E. Assessment of the Short-Term Effectiveness of Kinesiotaping and Trigger Points Release Used in Functional Disorders of the Masticatory Muscles. Pain Res Manag. 2018 May 10;2018:5464985. [Medline: 29861804] [PMC free article: 5971356] [doi: 10.1155/2018/5464985]

33. Kasawara KT, Mapa JMR, Ferreira V, Added MAN, Shiwa SR, Carvas N Jr, Batista PA. Effects of Kinesio Taping on breast cancer-related lymphedema: A meta-analysis in clinical trials. Physiother Theory Pract. 2018 May;34(5):337-345. [Medline: 29308967] [doi: 10.1080/09593985.2017.1419522]

34. Pekyavaş NÖ, Tunay VB, Akbayrak T, Kaya S, Karataş M. Complex decongestive therapy and taping for patients with postmastectomy lymphedema: a randomized controlled study. Eur J Oncol Nurs. 2014 Dec;18(6):585-90. [Medline: 25066648] [doi: 10.1016/j.ejon.2014.06.010]

35. Windisch C, Brodt S, Röhner E, Matziolis G. Effects of Kinesio taping compared to arterio-venous Impulse System $^{\mathrm{TM}}$ on limb swelling and skin temperature after total knee arthroplasty. Int Orthop. 2017 Feb;41(2):301-307. [Medline: 27688220] [doi: 10.1007/s00264-016-3295-z]

36. Ristow O, Pautke C, Victoria Kehl, Koerdt S, Schwärzler K, Hahnefeld L, Hohlweg-Majert B. Influence of kinesiologic tape on postoperative swelling, pain and trismus after zygomatico-orbital fractures. J Craniomaxillofac Surg. 2014 Jul;42(5):469-76. [Medline: 23830769] [doi: 10.1016/j.jcms.2013.05.043]

37. Tozzi U, Santagata M, Sellitto A, Tartaro GP. Influence of Kinesiologic Tape on Post-operative Swelling After Orthognathic Surgery. J Maxillofac Oral Surg. 2016 Mar;15(1):52-8. [Medline: 26929553] [doi: 10.1007/s12663-015-0787-0]

38. Thelen MD, Dauber JA, Stoneman PD. The clinical efficacy of kinesio tape for shoulder pain: a randomized, double-blinded, clinical trial. J Orthop Sports Phys Ther. 2008 Jul;38(7):389-95. [Medline: 18591761] [doi: 10.2519/jospt.2008.2791]

39. Ristow O, Hohlweg-Majert B, Stürzenbaum SR, Kehl V, Koerdt S, Hahnefeld L, Pautke C. Therapeutic elastic tape reduces morbidity after wisdom teeth removal--a clinical trial. Clin Oral Investig. 2014 May;18(4):1205-1212. [Medline: 23963616] [doi: 10.1007/s00784-013-1067-3]

40. Lietz-Kijak D, Kijak E, Krajczy M, Bogacz K, Łuniewski J, Szczegielniak J. The Impact of the Use of Kinesio Taping Method on the Reduction of Swelling in Patients After Orthognathic Surgery: A Pilot Study. Med Sci Monit. 2018 Jun 4;24:3736-3743. [Medline: 29861496] [doi: 10.12659/MSM.909915]

41. Ristow O, Hohlweg-Majert B, Kehl V, Koerdt S, Hahnefeld L, Pautke C. Does elastic therapeutic tape reduce postoperative swelling, pain, and trismus after open reduction and internal fixation of mandibular fractures? J Oral Maxillofac Surg. 2013 Aug;71(8):1387-96.. [Medline: 23676774] [doi: 10.1016/j.joms.2013.03.020]

42. Meisami T, Musa M, Keller MA, Cooper R, Clokie CM, Sàndor GK. Magnetic resonance imaging assessment of airway status after orthognathic surgery. Oral Surg Oral Med Oral Pathol Oral Radiol Endod. 2007 Apr;103(4):458-63. [Medline: 17395062$]$ [doi: $10.1016 /$ j.tripleo.2006.07.006]

43. Koparal M, Kucuk AO, Alan H, Asutay F, Avci M. Effects of low-level laser therapy following surgical extraction of the lower third molar with objective measurement of swelling using a three-dimensional system. Exp Ther Med. 2018 Apr;15(4):3820-3826. [Medline: $\underline{29581740}$ ] [PMC free article: $\underline{5863601}$ ] [doi: $10.3892 / \mathrm{etm} .2018 .5921]$

44. Çebi AT, Kasapoğlu MB, Eren S, Kasapoğlu Ç. Comparison of the effects of diclofenac potassium and tenoxicam on postoperative pain, swelling, and trismus following third molar surgery. Turk J Med Sci. 2018 Apr 30;48(2):271-278. [Medline: 29714439] [doi: 10.3906/sag-1702-100]

45. Wong JY, Oh AK, Ohta E, Hunt AT, Rogers GF, Mulliken JB, Deutsch CK. Validity and reliability of craniofacial anthropometric measurement of 3D digital photogrammetric images. Cleft Palate Craniofac J. 2008 May;45(3):232-9. [Medline: 18452351] [doi: 10.1597/06-175]

46. Nord F, Ferjencik R, Seifert B, Lanzer M, Gander T, Matthews F, Rücker M, Lübbers HT. The 3dMD photogrammetric photo system in cranio-maxillofacial surgery: Validation of interexaminer variations and perceptions. J Craniomaxillofac Surg. 2015 Nov;43(9):1798-803. [Medline: 26421470] [doi: 10.1016/j.jcms.2015.08.017]

\section{To cite this article:}

Ulu M, Gözlüklü Ö, Kaya Ç, Ünal N, Akçay H.

Three-Dimensional Evaluation of the Effects of Kinesio Taping on Postoperative Swelling and Pain after Surgically Assisted Rapid Palatal Expansion J Oral Maxillofac Res 2018;9(4):e3

URL: http://www.ejomr.org/JOMR/archives/2018/4/e3/v9n4e3.pdf doi: $\underline{10.5037 / \text { jomr.2018.9403 }}$ 
Copyright @ Ulu M, Gözlüklü Ö, Kaya Ç, Ünal N, Akçay H. Published in the JOURNAL OF ORAL \& MAXILLOFACIAL RESEARCH (http://www.ejomr.org), 30 December 2018.

This is an open-access article, first published in the JOURNAL OF ORAL \& MAXILLOFACIAL RESEARCH, distributed under the terms of the Creative Commons Attribution-Noncommercial-No Derivative Works 3.0 Unported License, which permits unrestricted non-commercial use, distribution, and reproduction in any medium, provided the original work and is properly cited. The copyright, license information and link to the original publication on (http://www.ejomr.org) must be included. 